\title{
The Brain Correlates of Laugh and Cataplexy in Childhood Narcolepsy
}

\author{
Stefano Meletti, ${ }^{1,2}$ Anna Elisabetta Vaudano, ${ }^{1,2}$ Fabio Pizza, ${ }^{3,4}$ Andrea Ruggieri, ${ }^{1}$ Stefano Vandi, ${ }^{3,4}$ Alberto Teggi, ${ }^{1}$ \\ Christian Franceschini, ${ }^{5}$ Francesca Benuzzi, ${ }^{1}$ PPaolo Frigio Nichelli, ${ }^{1,2}$ and Giuseppe Plazzi ${ }^{3,4}$ \\ ${ }^{1}$ Department of Biomedical, Metabolic, and Neural Sciences, University of Modena and Reggio Emilia, 41100 Modena, Italy, ${ }^{2}$ N.O.C.S.A.E. Hospital, AUSL \\ 41100 Modena, Italy, ${ }^{3}$ Department of Biomedical and Neuromotor Sciences, University of Bologna, 40123 Bologna, Italy, ${ }^{4}$ IRCCS Istituto delle Scienze \\ Neurologiche, AUSL di Bologna, 40123 Bologna, Italy, and ${ }^{5}$ Department of Clinical and Experimental Medicine, University of Parma, 43121 Parma, Italy
}

The brain suprapontine mechanisms associated with human cataplexy have not been clarified. Animal data suggest that the amygdala and the ventromedial prefrontal cortex are key regions in promoting emotion-induced cataplectic attacks. Twenty-one drug-naive children/adolescent (13 males, mean age 11 years) with recent onset of narcolepsy type 1 (NT1) were studied with fMRI while viewing funny videos using a "naturalistic" paradigm. fMRI data were acquired synchronously with EEG, mylohyoid muscle activity, and the video of the patient's face. Whole-brain hemodynamic correlates of (1) a sign of fun and amusement (laughter) and of (2) cataplexy were analyzed and compared. Correlations analyses between these contrasts and disease-related variables and behavioral findings were performed.

Emotion-induced laughter occurred in 16 patients, and of these 10 showed cataplexy for a total of 77 events (mean duration $=4.4 \mathrm{~s}$ ). Cataplexy was marked by brief losses of mylohyoid muscle tone and by the observation of episodes of facial hypotonia, jaw drop, and ptosis. During laughter (without cataplexy) an increased hemodynamic response occurred in a bilateral network involving the motor/ premotor cortex and anterior cingulate gyrus. During cataplexy, suprapontine BOLD signal increase was present in the amygdala, frontal operculum-anterior insular cortex, ventromedial prefrontal cortex, and the nucleus accumbens; BOLD signal increases were also observed at locus ceruleus and in anteromedial pons. The comparison of cataplexy versus laugh episodes revealed the involvement of a corticolimbic network that processes reward and emotion encompassing the anterior insular cortex, the nucleus accumbens, and the amygdala.

Key words: cataplexy; emotion; fMRI; humor; narcolepsy; sleep disorders

\section{Significance Statement}

In this study we reported for the first time in humans the brain structures whose neural activity is specifically and consistently associated with emotion-induced cataplexy. To reach this goal drug-naive children and adolescents with recent onset narcolepsy type 1 were investigated. In narcolepsy caused by hypocretin/orexin deficiency, cataplexy is associated with a marked increase in neural activity in the amygdala, the nucleus accumbens, and the ventromedial prefrontal cortex, which represent suprapontine centers that physiologically process emotions and reward. These findings confirm recent data obtained in the hypocretin knockout mice and suggest that the absence of hypothalamic hypocretin control on mesolimbic reward centers is crucial in determining cataplexy induced by emotions.

\section{Introduction}

Narcolepsy type 1 (NT1) is a rare, life-long central disorder of excessive daytime sleepiness (EDS) that frequently arises in child-

\section{Received March 2, 2015; revised May 29, 2015; accepted July 10, 2015.}

Author contributions: S.M., A.E.V., P.F.N., and G.P. designed research; S.M., A.E.V., F.P., A.R., S.V., A.T., C.F., and F.B. performed research; S.M., A.E.V., F.P., A.R., S.V., A.T., and C.F. analyzed data; S.M., A.E.V., and G.P. wrote the paper.

We are indebted to all young patients and families participating in this study, most notably the Italian Association of Narcolepsy (AIN onlus) patients. Without their contributions, this study would not have been possible. We thank P. Baraldi and G. Pagnoni for their help and suggestions in fMRI data analysis. hood or adolescence peaking at 15 years old (Dauvilliers et al., 2007), and is prevalent between 25 and 50 people per 100,000 in the adult population (Longstreth et al., 2007). The core NT1 symptoms are EDS, cataplexy, sleep paralysis, hallucinations, and fragmented nocturnal sleep (American Academy of Sleep Medicine, 2014). Cataplexy is pathognomonic of NT1 and is defined as Biomediche e Neuromotorie (DIBINEM), Università di Bologna, Via Ugo Foscolo 7, 40123 Bologna, Italy, 
Table 1. Clinical, polysomnographic, and laboratory data of investigated patients

\begin{tabular}{|c|c|c|c|c|c|c|c|c|c|}
\hline $\begin{array}{l}\text { Patient } \\
\text { number }\end{array}$ & $\begin{array}{l}\text { Age (years)/ } \\
\text { sex }\end{array}$ & $\begin{array}{l}\text { Disease duration } \\
\text { (years) }\end{array}$ & $\begin{array}{l}\text { Time since cataplexy } \\
\text { onset (years) }\end{array}$ & $\begin{array}{l}\text { Cataplectic attack } \\
\text { frequency }^{a}\end{array}$ & $\begin{array}{l}\text { MSLT } \\
\text { (min) }\end{array}$ & MSLT-SOREMPS & $\begin{array}{l}\text { CSF Hcrt } \\
\mathrm{pg} / \mathrm{ml}\end{array}$ & $\mathrm{ESS}^{a}$ & HLA-DQB1*0602 \\
\hline 1 & $13 / \mathrm{F}$ & 2 & 1 & 1/week-1/d & 3.30 & 5 & 10.7 & 13 & $\mathrm{p}$ \\
\hline 2 & $11 / M$ & 4 & 2 & 1/year-1/month & 9.00 & 5 & 43.1 & 13 & p \\
\hline 3 & $14 / F$ & 3 & 2 & 1/week-1/d & 2.40 & 5 & 0 & 13 & p \\
\hline 4 & $10 / M$ & 2 & 1 & $>1 / d$ & 1.90 & 4 & 0 & 21 & $\mathrm{p}$ \\
\hline 5 & $10 / \mathrm{F}$ & 4 & 2 & $>1 / d$ & 1.20 & 1 & 15.5 & 14 & p \\
\hline 6 & $9 / M$ & 0 & 0 & $>1 / d$ & 1.90 & 5 & 0 & 16 & p \\
\hline 7 & $15 / M$ & 5 & 2 & $1 /$ week-1/d & 3.30 & 4 & 0 & 17 & p \\
\hline 8 & $9 / \mathrm{F}$ & 0 & 0 & $>1 / d$ & 4.40 & 2 & 0 & 14 & p \\
\hline 9 & $12 / F$ & 1 & 1 & $>1 / d$ & 1.70 & 3 & 33 & 10 & $\mathrm{p}$ \\
\hline 10 & $11 / \mathrm{F}$ & 1 & 1 & $1 /$ week-1/d & 1.00 & 5 & 0 & 14 & $\mathrm{p}$ \\
\hline 11 & $11 / M$ & 3 & 2 & $>1 / d$ & 9.80 & 4 & 25 & 14 & p \\
\hline 12 & $11 / M$ & 3 & 1 & $1 /$ week-1/d & 2.20 & 5 & 13.6 & 11 & p \\
\hline 13 & $13 / M$ & 3 & 2 & $>1 / d$ & 13.00 & 4 & 55 & 19 & $\mathrm{p}$ \\
\hline 14 & $11 / \mathrm{F}$ & 1 & 1 & $>1 / d$ & 8.90 & 3 & 84.2 & 12 & p \\
\hline 15 & $7 / F$ & 1 & 1 & $>1 / \mathrm{d}$ & 9.60 & 1 & 0 & 20 & p \\
\hline 16 & $16 / M$ & 4 & 2 & $1 /$ week-1/d & 2.40 & 5 & 0 & 13 & $p$ \\
\hline 17 & $14 / M$ & 2 & 1 & $>1 / d$ & 2.00 & 5 & 10.5 & 21 & p \\
\hline 18 & $8 / M$ & 1 & 0 & $1 /$ week-1/d & 4.00 & 1 & 0 & 14 & p \\
\hline 19 & $15 / M$ & 3 & 1 & $>1 / d$ & 7.00 & 3 & 0 & 12 & $p$ \\
\hline 20 & $9 / M$ & 0 & 1 & $1 /$ week-1/d & 3.50 & 4 & 20 & 9 & p \\
\hline 21 & $8 / M$ & 2 & 2 & $>1 / d$ & 2.00 & 2 & 40 & 18 & p \\
\hline
\end{tabular}

F, female; M, male; Hcrt, hypocretin-1 level in CSF (pathological levels $<110 \mathrm{pg} / \mathrm{ml}$ ); ESS is range $0-24$, pathological score $>10$; , positive HLA-DQB1* 0602 allele. ${ }^{a}$ Before the fMRI scan sessions, the ESS score and the frequency of cataplexy were assessed in each patient.

sudden episodes of muscle weakness occurring during wakefulness, typically triggered by strong emotions of positive valence (most often by laughter). In addition to cataplexy, the rapid transition from wakefulness to REM sleep is the polysomnographic marker of NT1. Patients with NT1 have difficulty in executing daily activities, socializing, and maintaining personal relationships because of cataplexy and somnolence. NT1 is caused by a lack of wake-promoting hypocretin (orexin) signaling, resulting from the loss of hypocretinergic neurons in the dorsolateral hypothalamus and leading to reduced or absent CSF hypocretin-1 (Peyron et al., 2000; Thannickal et al., 2000). The cause of hypocretin-producing cell loss is still under investigation and an autoimmune mechanism is the most likely etiological hypothesis (Partinen et al., 2014).

Cataplexy can occur with either partial or global involvement of all skeletal muscles, except the diaphragm and extraocular muscles (Overeem et al., 2011). Typically, partial attacks induce slurred speech, facial weakness and twitching of the facial muscles, and jaw or head dropping, whereas global attacks can lead to generalized muscular involvement resulting in falls to the ground (Rubboli et al., 2000; Vetrugno et al., 2010).

While brainstem mechanisms regulating cataplexy in animals have been partly clarified, the suprapontine mechanisms that induce cataplexy are largely unknown. Only recently, a key role of the amygdala and ventomedial prefrontal cortex (VMPFC) has been shown in the induction of emotionally triggered cataplectic attacks in the hypocretin knock-out mice (Hcrt ${ }^{-1-}$ mice; Burgess et al., 2013; Oishi et al., 2013; Dauvilliers et al., 2014).

In humans, the existence of a link between cataplexy and emotions was postulated long ago. Neuroimaging studies demonstrated that NT1 patients have an abnormal hemodynamic response in processing humorous or rewarding stimuli (Reiss et

E-mail: giuseppe.plazzi@unibo.it; or Stefano Meletti, Department of Biomedical, Metabolic, and Neural Science, University of Modena and Reggio Emilia, NOCSAE Hospital, via Giardini 1355, 41126 Modena, Italy, E-mail: stefano.meletti@unimore.it.

DOI:10.1523/JNEUROSCI.0840-15.2015

Copyright $\odot 2015$ the authors $\quad 0270-6474 / 15 / 3511584-12 \$ 15.00 / 0$ al., 2008; Schwartz et al., 2008; Ponz et al., 2010b). In particular, an increased amygdala activity compared with healthy controls has been observed. Moreover, abnormal behavior in the subcortical mesolimbic reward network (including nucleus accumbens, ventral tegmental area, and hypothalamus) seems present in NT1 patients during high reward expectancy (Ponz et al., 2010a).

However, few studies characterized in humans the neural correlates during typical cataplectic attacks induced by emotional stimuli. In fact, only anecdotal case reports have been described, with conflicting findings (Hong et al., 2006; Chabas et al., 2007; Reiss et al., 2008; Dauvilliers et al., 2010). This paucity of data reflects how difficult it is to evoke a cataplectic attack in a controlled setting (such as during an fMRI experiment). Moreover, the available data were often obtained in adult patients under drug treatment or during cataplectic status after antidepressant withdrawal; therefore they are not representative of genuine emotionally triggered cataplexy.

In the attempt to fill this gap, we investigated the neural networks associated with laughter-induced cataplexy using the BOLD signal changes that occurred while viewing prolonged funny videos in a "naturalistic" fMRI paradigm in drug-naive children and adolescents with NT1 close to disease onset.

\section{Materials and Methods}

\section{Participants}

Patients were proposed to participate in the fMRI study if the following inclusion criteria were satisfied: (1) drug-naive children from 8 to 16 years old with NT1, (2) a diagnosis of NT1 according to the current criteria (American Academy of Sleep Medicine, 2014), (3) proven CSF hypocretin-1 deficiency, (4) cataplexy onset for no more than 2 years, and (5) video documentation of cataplectic attacks during a standardized video session (Plazzi et al., 2011; Pizza et al., 2013) no longer than 6 months before the neuroimaging experimental sessions.

From January 2014 to February 2015, 21 patients (13 males, mean age $11.3 \pm 2.5$ years) fulfilled the inclusion criteria and agreed to participate in the fMRI study. All subjects were right-handed (Oldfield, 1971). Table 1 reports the patients' clinical data. All patients had a complete clinical and neurological examination, conventional brain MRI, and underwent a $48 \mathrm{~h}$ continuous polysomnographic recording followed by a standard 
A

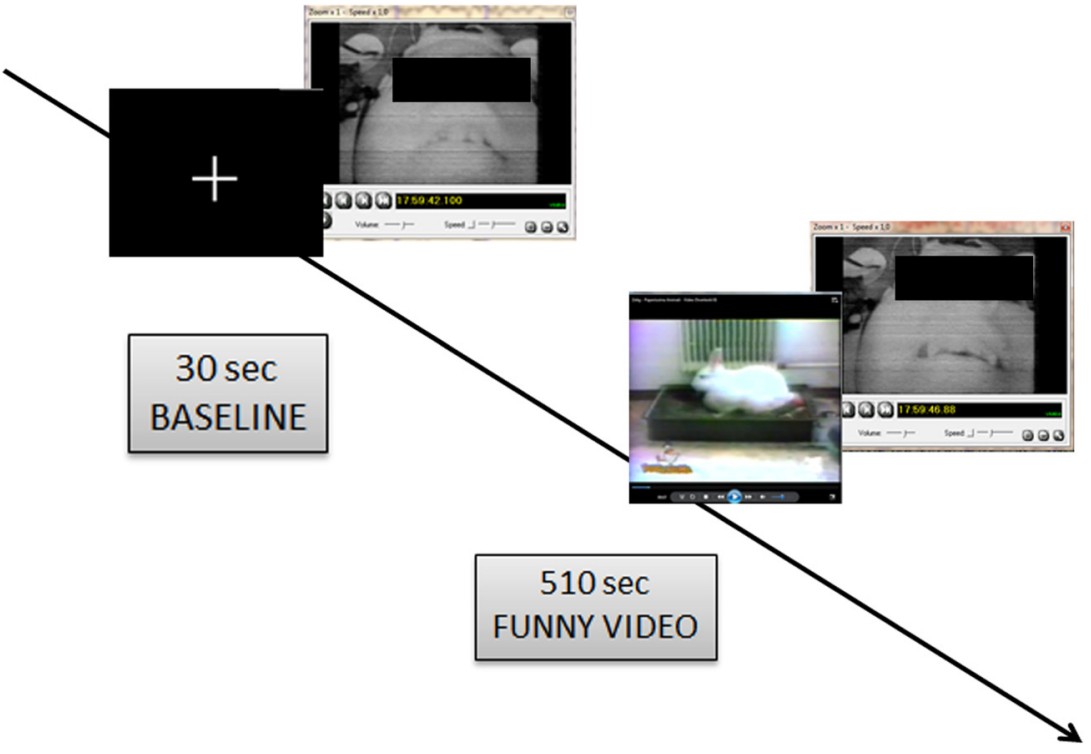

B

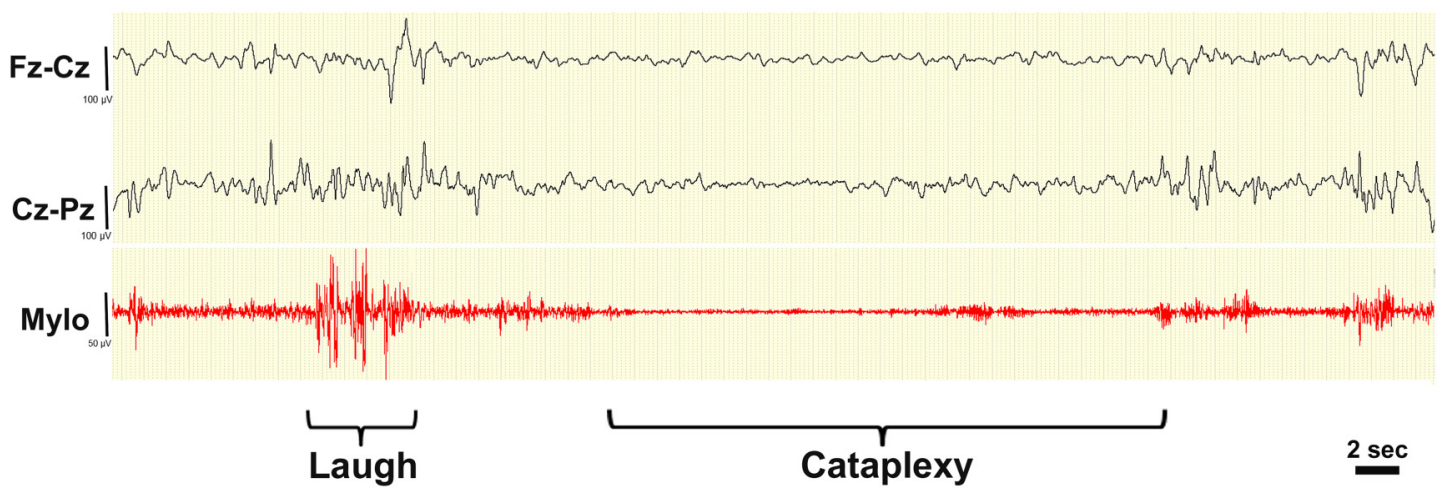

Figure 1. Representation of the polygraphic fMRI protocol. $A$, Each fMRI run was organized in $30 \mathrm{~s}$ of baseline during which the patient was instructed to watch a white cross on a black screen followed by one funny video. Each video was $8 \mathrm{~min}$ and $30 \mathrm{~s}$ and the relative fMRI scan time was $510 \mathrm{~s}$. Two to three fMRI runs were repeated in each session for every patient. Baseline/laughter/ cataplexy and physiological facial movements (see Materials and Methods) were monitored throughout by a small camcorder pointing at the patient's face. $\boldsymbol{B}, \mathrm{A} 60 \mathrm{~s}$ representative page of video-polygraphy ( $32 \mathrm{EEG}$ channels plus 2 channels for EMG and ECG, respectively) recorded simultaneously during fMRI acquisitions, after off-line gradient artifact suppression and ballistocardiogram removal. The midline EEG electrodes ( $\mathrm{Fz}, \mathrm{Cz}$, and Pz) are displayed in a bipolar montage. Surface EMG activity is recorded from the mylohyoid muscle. Note the burst of EMG activity during the laugh and the transient loss of muscle tone during cataplexy with rapid rebound after it.

five-nap Multiple Sleep Latency Test (MSLT; Littner et al., 2005) and video recordings of cataplexy as previously described (Plazzi et al., 2011; Pizza et al., 2013). Before each video session, patients were interviewed to determine their humor preferences and asked to choose between various funny videos; these were selected to best stimulate each subject. Video recordings included a $5 \mathrm{~min}$ baseline followed by $30 \mathrm{~min}$ while subjects were watching videos; children were sitting and/or standing for 10-40 min, enough time for the child to feel at ease but not long enough for the child to feel sleepy. Two experts in the field narcolepsy (F.P. and G.P.) independently analyzed the video recordings and rated the presence of paroxysmal "negative" motor symptoms during emotional stimulation. HLA-DQB1 ${ }^{\star} 0602$ typing was conducted in all patients. Cataplexy frequency was assessed and subjective sleepiness was quantified by a modified version of the Epworth Sleepiness Scale (mESS; Melendres et al., 2004).

The study was performed according to the Declaration of Helsinki and approved by the local ethical committee; consent was obtained from parents and assent obtained from patients.

Polygraphic functional imaging protocol

Stimuli. To maximize the chance of recording cataplexy in a "hostile" environment like the MRI scanner, we adopted a patient-specific proto- col by selecting the funny videos that were previously successful in the standardized video session. Videos were digitally recorded and edited to remove commercials. The resulting videos were $8 \mathrm{~min}$ and $30 \mathrm{~s}$ in length. Patients were scanned while passively viewing an entire video without any specific task requirement. We told patients they should try to keep their head fixed, but they could smile or even laugh if the comic was funny, and that they did not have to suppress emotions. Two to three videos were presented to each patient. Following the scan, each subject was asked to rate each cartoon for humor intensity (i.e., degree of funniness) on a scale of 1 to 10 , with 1 and 10 as the least and most funny, respectively. Figure $1 A$ is a schematic representation of the fMRI protocol.

Recordings. Data acquisition was performed in a dimly lit room during the afternoon. Patients were asked to take a brief nap before the recordings to reduce sleepiness to avoid its confounding effects. Scalp EEG (1024 Hz sampling rate) was recorded by a 32-channel MRI-compatible EEG recording system (Micromed). EKG activity was recorded from electrodes positioned over the chest; surface EMG was recorded from subchin electrodes. Foam pads were used to help secure the EEG leads, minimize motion, and improve the patient's comfort. EEG recording was relevant to exclude objective signs of sleepiness/sleep onset. The 
patient was constantly observed and recorded with a small camcorder positioned on the head coil inside the scanner pointing to the patient's face to obtain a split-screen video-polygraphic documentation during the fMRI recording (Ruggieri et al., 2015). The simultaneously recorded video during scanning allowed patients to be checked for physiological facial movements, laughter, and the appearance of cataplexy. For the purpose of our work, chin EMG and video recordings were essential for recognizing the exact time and duration of each cataplectic event.

Functional data were acquired using the Philips Intera system at $3 \mathrm{~T}$ and a gradient-echo echo-planar sequence from 30 axial contiguous slices $(\mathrm{TR}=2.000 \mathrm{~ms}, \mathrm{TE}=35 \mathrm{~ms}$, in-plane matrix $=80 \times 80$, voxel size $=3 \times 3 \times 3 \mathrm{~mm}$ ) over two to three $8 \mathrm{~min} 30 \mathrm{~s}$ runs $(255$ volumes per run) with continuous simultaneous video-polygraphic recording. A high-resolution T1-weighted anatomic image was acquired for anatomical reference and volumetric analysis. The volume consisted of 170 sagittal slices $(\mathrm{TR}=9.9 \mathrm{~ms}, \mathrm{TE}=4.6 \mathrm{~ms}$, in plane matrix $=256 \times 256$, voxel size $=1 \times 1 \times 1 \mathrm{~mm}$ ).

\section{Video-polygraphic data analysis}

After off-line correction of the gradient artifacts and filtering of the EEG signal, the EEG data were reviewed and preprocessed according to previous published methods (Avanzini et al., 2014; Vaudano et al., 2014). EMG activity from the mylohyoid muscle was filtered between 50 and $500 \mathrm{~Hz}$.

Three sleep medicine experts in NT1 (G.P., F.P., and S.V.) reviewed the cataplexy video recordings obtained in the sleep laboratory, and they collegially identified the main facial features and the polygraphic picture of the cataplectic attacks for each patient. They subsequently reviewed the video-polygraphic recordings obtained during the fMRI procedure independently to identify the onsets and offsets of the events of interest for the study including (1) laughter and smiles and (2) cataplectic "negative motor" phenomena. We considered "cataplectic attacks" only the events for which the judgments of the raters were concordant. In case of disagreement, the clinical features of cataplectic attacks of that patient, as recorded in the sleep laboratory, were reviewed and compared with the events recorded in the scan. Only when a consensus was reached was the event considered a "cataplectic event" to minimize the risk of falsepositive events.

\section{fMRI data analysis}

The MATLAB 7.1 and SPM8 (Wellcome Trust Center for Neuroimaging, University College London) software was used for whole-brain fMRI data analysis. All functional volumes were slice-time corrected, realigned to the first volume acquired, normalized to the MNI template, and smoothed with $8 \times 8 \times 8 \mathrm{~mm}$ FWHM Gaussian kernel. No subject was excluded from subsequent analysis for excessive head motion.

To provide the hemodynamic maps of "laughter" and "cataplexy," the fMRI data were analyzed within the GLM framework. For each EPI session one GLM was constructed including (1) the effects of interest (laughter and/or cataplexy), represented as blocks (with duration defined by the video) convolved with canonical hemodynamic response function; (2) the confounds, represented by 24 realignment parameters (six scan realignment parameters from image preprocessing and a Volterra expansion of these; Friston et al., 1996); and (3) the video-based physiologic facial movements (i.e., swallowing; Chaudhary et al., 2012; Ruggieri et al., 2015).

To further assess the influence of head motion, and especially to test if movement affected one condition significantly more than others (i.e., laughter or cataplexy), we quantified head motion for each subject across the entire scanning session by computing vector distances (derived from the $x, y$, and $z$ translational realignment corrections) between sequential functional volumes (Moran et al., 2004). Vector distances for each time point for each subject were then assigned to "laughter," "cataplexy," and "baseline" conditions and submitted to one-way ANOVA.

Statistical parametric maps were generated from linear contrasts between conditions in each participant (laughter $>$ baseline; cataplexy $>$ baseline; cataplexy $>$ laughter). The contrast images from each subject were then submitted to a second-level group analysis using the randomeffect approach (Friston et al., 1999).
The threshold for statistical significance was set at $p<0.05$ corrected for false discovery rate (FDR) or $p<0.001$ uncorrected if the BOLD maps did not reveal any change at the more conservative threshold. In these uncorrected maps, an extent threshold of five contiguous voxels was applied. The resulting statistical maps were displayed in MNI space.

Finally, we performed additional whole-brain second-level correlation analyses to test for a linear relation between BOLD signal changes relative to brain responses to humor and the main clinical measurements, including age at disease onset, duration of disease, cataplexy frequency, ESS score, mean sleep latency, and number of sleep-onset rapid eye movement periods (SOREMPs) at the MSLT. We also analyzed possible correlations between BOLD signal changes and the number of observed smiles/laughter events during scanning and the postscanning ratings of the videos. These analyses allowed us to assess whether the modulation of brain responses to humor might relate to individual clinical characteristics and to behavioral variables observed during the fMRI experiment.

\section{Results}

\section{Behavior}

We recorded 77 cataplectic events in 10 patients (Table 2 shows the detailed behavioral results for each patient and fMRI run). The mean duration of cataplexy was $4.4 \mathrm{~s}$, ranging from $2.1 \mathrm{~s}$ (Patient 17) to $5.5 \mathrm{~s}$ (Patients 9 and 19). Cataplexy was preceded by signs of fun in every attack, such as a smile or laugh. The video recordings acquired during the $\mathrm{fMRI}$ procedure allowed us to recognize in each patient the typical pathological facial features that characterize childhood cataplexy: episodes of facial hypotonia, jaw drop, tongue protrusion, and ptosis (i.e., the "cataplectic facies”; Serra et al., 2008; Plazzi et al., 2011; Pizza et al., 2013).

In these 10 patients smiles and laughter without signs of cataplexy also were recorded (214 events). In the remaining 11 patients no cataplexy was observed during stimulation. Six of the latter patients showed laughter (28 events), while five did not show any facial display of fun and amusement.

The mean \pm SD of postscanning ratings of video funniness was $7.2 \pm 2$ for the scanning runs with emotion-induced cataplexy and $4.8 \pm 2.6$ for runs without cataplexy $(t=3.56, p<$ $0.001)$. The mean number of smiles/laughter bouts was $14.7 \pm$ 8.5 in the runs with emotion-induced cataplexy and $5.5 \pm 4.6$ in the runs without cataplexy $(t=3.90, p<0.001)$.

Video-EEG recordings showed that EEG and behavioral signs of sleepiness and sleep never occurred during sessions. Finally, no differences in head motion were recorded among cataplexy $(0.45 \pm 0.29 \mathrm{~mm})$, laughter $(0.42 \pm 0.20 \mathrm{~mm})$, and baseline vision $\left(0.40 \pm 0.25 \mathrm{~mm} ; F_{(2,22)}=0.06, p>0.8\right)$.

\section{Brain correlates of cataplexy}

Group-level brain correlates of cataplexy were obtained by a random-effect approach across the 10 patients with emotionrelated cataplectic events.

BOLD signal increases were observed (Fig. $2 A$, Table 3 ) in a cortical and subcortical network that included the bilateral (>right) insular cortex/frontal operculum, anterior cingulate cortex, VMPFC, amygdala, posterior thalamic nuclei, and mesolimbic reward regions including the nucleus accumbens and ventral striatum. Moreover, brainstem BOLD signal increases were observed in the posterolateral pontomesencephalic region (locus ceruleus) and in the anteromedial pons. Peristimulus time histograms (PSTHs) were calculated at the cluster peak ( sphere $=10 \mathrm{~mm}$ ) of right amygdala, anterior insular cortex (AIC), and VMPFC to show the time course of the hemodynamic response (Fig. $2 B$ ). The analysis emphasizes a prominent increase in BOLD signal in these structures with a peak at $4-6 \mathrm{~s}$ postevent onset. 
Table 2. Behavioral findings of NT1 patients during EEG-fMRI

\begin{tabular}{|c|c|c|c|c|c|c|}
\hline Patient number & $\begin{array}{l}\text { Run } \\
\text { number }\end{array}$ & $\begin{array}{l}\text { Rating of } \\
\text { videos }\end{array}$ & $\begin{array}{l}\text { Laughter bouts } \\
(n)\end{array}$ & $\begin{array}{l}\text { Laughter bouts } \\
\text { (mean duration; } s \text { ) }\end{array}$ & $\begin{array}{l}\text { cataplexy attacks } \\
(n)\end{array}$ & $\begin{array}{l}\text { Cataplexy attack } \\
\text { (mean duration; s) }\end{array}$ \\
\hline \multicolumn{7}{|c|}{ Runs with laughter and cataplexy $(n=15)$} \\
\hline 2 & 1 & 8 & 22 & 3.5 & 15 & 3.4 \\
\hline 4 & 1 & 10 & 3 & 4 & 4 & 5.2 \\
\hline 6 & 1 & 8 & 27 & 5.5 & 6 & 4.2 \\
\hline 6 & 2 & 7 & 6 & 5.8 & 2 & 4 \\
\hline 9 & 1 & 10 & 5 & 5.1 & 4 & 5.5 \\
\hline 13 & 1 & 7 & 17 & 4.3 & 6 & 3.2 \\
\hline 15 & 1 & 5 & 16 & 2.2 & 5 & 4 \\
\hline 15 & 2 & 5 & 17 & 3.2 & 4 & 3.5 \\
\hline 16 & 1 & 7 & 13 & 4.5 & 6 & 4.5 \\
\hline 16 & 2 & 4 & 2 & 3 & 4 & 5 \\
\hline 17 & 1 & 9 & 25 & 3.8 & 3 & 2.1 \\
\hline 17 & 2 & 5 & 30 & 4 & 4 & 5 \\
\hline 19 & 1 & 8 & 8 & 5.1 & 4 & 5.5 \\
\hline 21 & 1 & 7 & 16 & 4 & 6 & 4.4 \\
\hline 21 & 2 & 8 & 10 & 5.2 & 4 & 6 \\
\hline \multicolumn{7}{|c|}{ Runs with smiles and laughter only $(n=14)$} \\
\hline 1 & 1 & 3 & 1 & 2 & $\mathrm{nr}$ & $\mathrm{nr}$ \\
\hline 1 & 2 & 2 & 7 & 2.5 & $\mathrm{nr}$ & $\mathrm{nr}$ \\
\hline 4 & 2 & 7 & 4 & 3.6 & $\mathrm{nr}$ & $\mathrm{nr}$ \\
\hline 5 & 2 & 4 & 7 & 4 & $\mathrm{nr}$ & $\mathrm{nr}$ \\
\hline 8 & 1 & 5 & 4 & 5 & $\mathrm{nr}$ & $\mathrm{nr}$ \\
\hline 8 & 2 & 4 & 2 & 2.5 & $\mathrm{nr}$ & $\mathrm{nr}$ \\
\hline 9 & 2 & 8 & 7 & 4 & $\mathrm{nr}$ & $\mathrm{nr}$ \\
\hline 11 & 1 & 3 & 1 & 3 & $\mathrm{nr}$ & $\mathrm{nr}$ \\
\hline 11 & 2 & 7 & 1 & 4 & $\mathrm{nr}$ & $\mathrm{nr}$ \\
\hline 12 & 1 & 7 & 1 & 4 & $\mathrm{nr}$ & $\mathrm{nr}$ \\
\hline 12 & 2 & 6 & 3 & 3.5 & $\mathrm{nr}$ & $\mathrm{nr}$ \\
\hline 13 & 2 & 6 & 16 & 4.5 & $\mathrm{nr}$ & $\mathrm{nr}$ \\
\hline 19 & 2 & 6 & 6 & 4.5 & $\mathrm{nr}$ & $\mathrm{nr}$ \\
\hline 20 & 1 & 9 & 17 & 3.9 & $\mathrm{nr}$ & $\mathrm{nr}$ \\
\hline \multicolumn{7}{|c|}{ Runs with no behavioral sign of amusement $(n=13)$} \\
\hline 2 & 2 & 3 & $\mathrm{nr}$ & $\mathrm{nr}$ & $\mathrm{nr}$ & $\mathrm{nr}$ \\
\hline 3 & 1 & 2 & $\mathrm{nr}$ & $\mathrm{nr}$ & $\mathrm{nr}$ & $\mathrm{nr}$ \\
\hline 3 & 2 & 4 & $\mathrm{nr}$ & $\mathrm{nr}$ & $\mathrm{nr}$ & $\mathrm{nr}$ \\
\hline 5 & 1 & 4 & $\mathrm{nr}$ & $\mathrm{nr}$ & $\mathrm{nr}$ & $\mathrm{nr}$ \\
\hline 5 & 3 & 3 & $\mathrm{nr}$ & $\mathrm{nr}$ & $\mathrm{nr}$ & $\mathrm{nr}$ \\
\hline 7 & 1 & 9 & $\mathrm{nr}$ & $\mathrm{nr}$ & $\mathrm{nr}$ & $\mathrm{nr}$ \\
\hline 7 & 2 & 4 & $\mathrm{nr}$ & $\mathrm{nr}$ & $\mathrm{nr}$ & $\mathrm{nr}$ \\
\hline 10 & 1 & 1 & $\mathrm{nr}$ & $\mathrm{nr}$ & $\mathrm{nr}$ & $\mathrm{nr}$ \\
\hline 10 & 2 & 1 & $\mathrm{nr}$ & $\mathrm{nr}$ & $\mathrm{nr}$ & $\mathrm{nr}$ \\
\hline 14 & 1 & 1 & $\mathrm{nr}$ & $\mathrm{nr}$ & $\mathrm{nr}$ & $\mathrm{nr}$ \\
\hline 18 & 1 & 9 & $\mathrm{nr}$ & $\mathrm{nr}$ & $\mathrm{nr}$ & $\mathrm{nr}$ \\
\hline 18 & 2 & 8 & $\mathrm{nr}$ & $\mathrm{nr}$ & $\mathrm{nr}$ & $\mathrm{nr}$ \\
\hline 20 & 2 & 5 & $\mathrm{nr}$ & $\mathrm{nr}$ & $\mathrm{nr}$ & $\mathrm{nr}$ \\
\hline
\end{tabular}

The mean duration of laughter bouts and cataplexy attack is expressed in seconds. Rating of the videos is based on a scale of 1 to 10 , where 1 is "not funny" and 10 is "most funny." nr, Not recorded.

The involvement of the amygdala, insula, and anterior cingulate/VMPFC, resulting from the random-effect approach, was supported by single-subject analyses: amygdala and insulapositive BOLD changes were detected in 8 of 10 patients (Table 4), while anterior cingulate/VMPFC BOLD increments were found in 9 of 10 cases. Brainstem BOLD-positive signal changes were observed in 6 of 10 patients (at $p<0.05 \mathrm{FDR}$ ). Using a less conservative threshold ( $p<0.001$, uncorrected) they were observed in every patient. Table 4 and Figure 3 detail the location of brainstem hemodynamic modifications at single-subject and group levels.

\section{Brain correlates of laughter}

Group-level (16 patients) brain correlates of laughter (without cataplexy) were detected over a cortical network encompassing bilaterally the motor-premotor cortex and the ACC (Fig. 4). No
BOLD changes were detected over the amygdala, insular cortex, and subcortical mesolimbic reward centers (see Table 3). In a further analysis, we considered separately the 14 runs (10 patients) during which only laughter occurred and the 15 runs (10 patients) in which laughter plus cataplexy occurred (in these runs cataplexy was included in the model and treated as a confound). Both analyses disclosed the involvement of a similar circuit related to laughter covering the bilateral motor network and ACC, confirming the whole-group results. No significant differences were detected between the two conditions at $p<0.05$ corrected for FDR and even at a less conservative threshold $(p<0.001$, uncorrected).

\section{What distinguishes cataplexy from laughter?}

When compared with laughter, cataplexy demonstrated a higher hemodynamic demand over a network of cortical and subcortical 
A
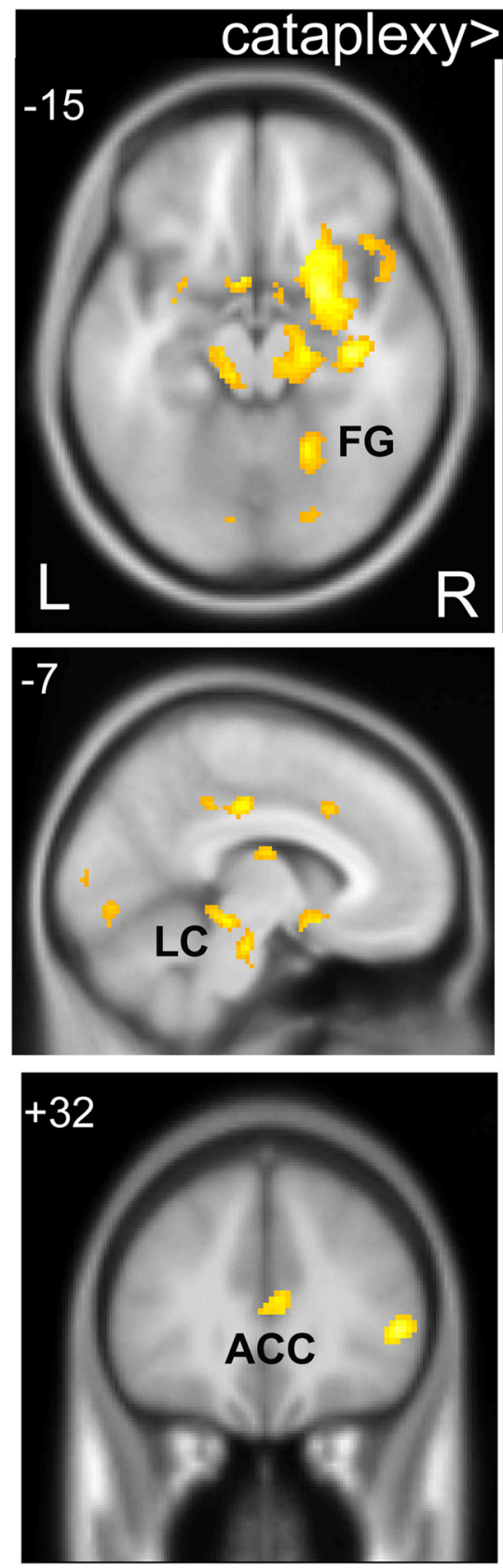

baseline
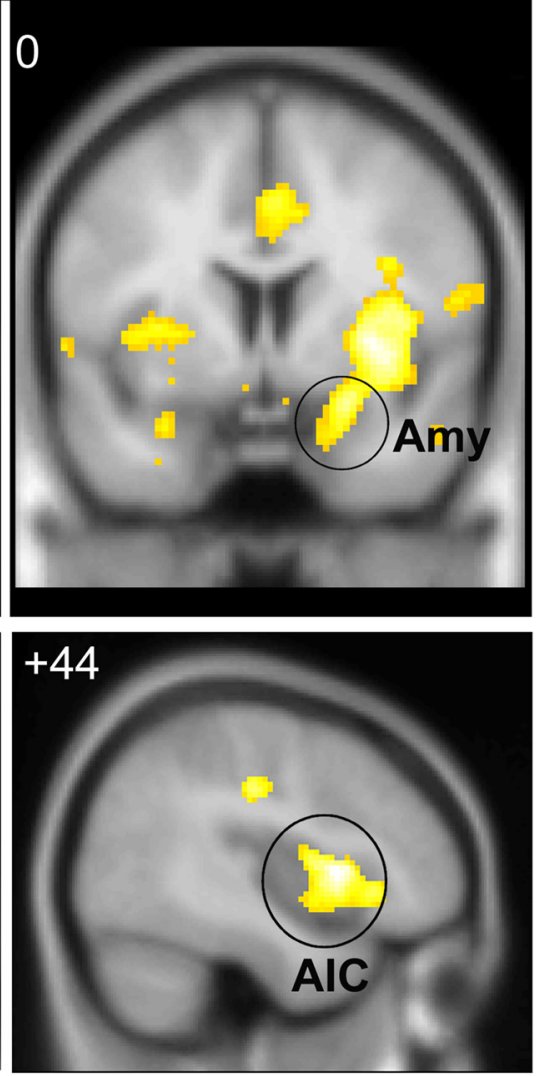

$+48$

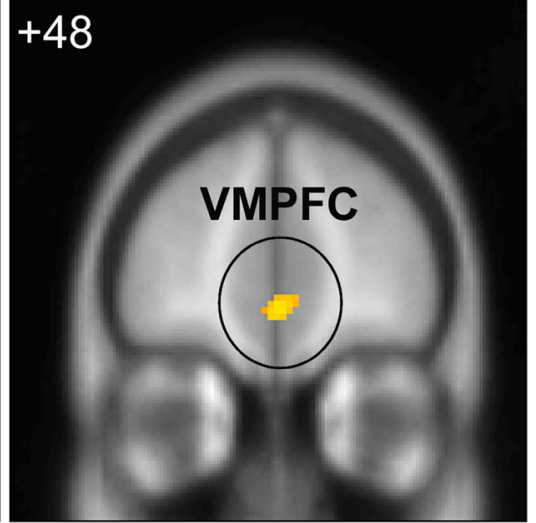

B
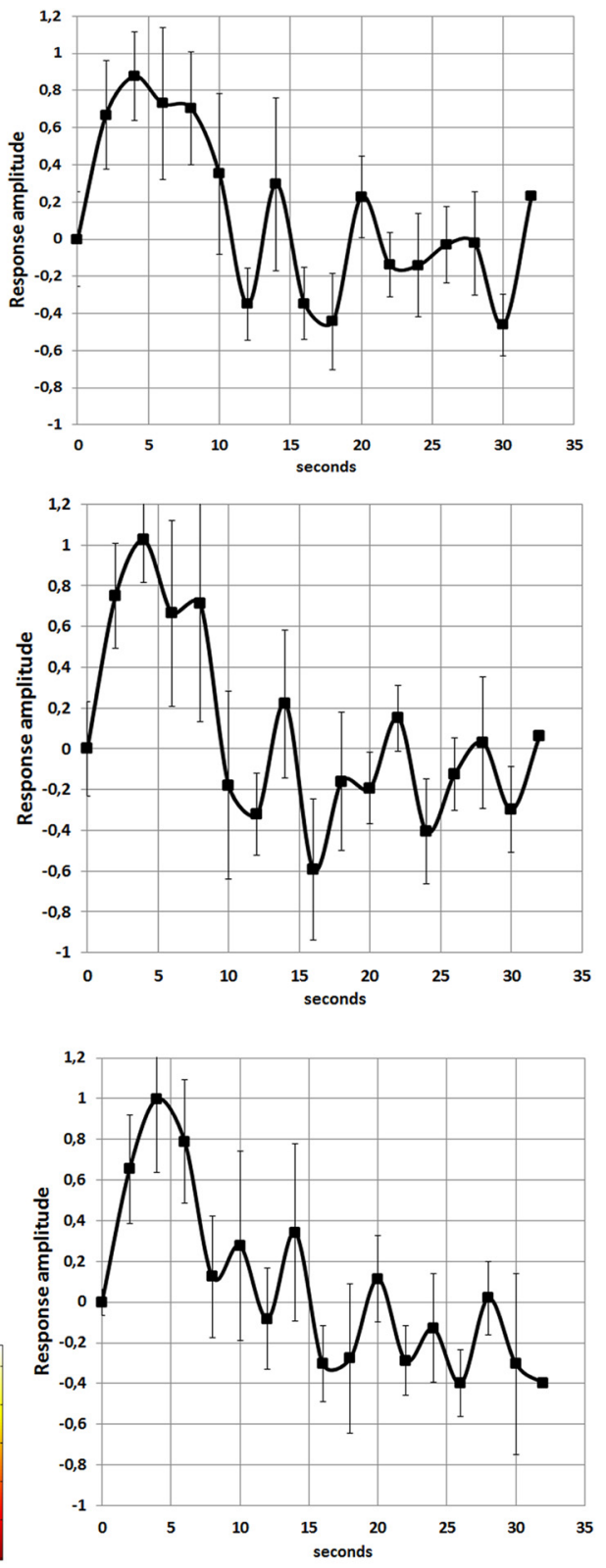

Figure 2. fMRI results related to cataplexy. $A$, Group-related (random-effect analysis) cataplexy-related BOLD findings. The BOLD changes ( $p<0.05$ corrected for FDR) are displayed on the axial, sagittal, and coronal T1-template image. See main text and Table 3 for details of activations. No decreases in BOLD signal were detected. L, left; R, right. B, PSTHs (solid black line; black error bars represent SEM) depicting the responses in right amygdala, right insula, and VMPFC (circles). PSTH provides a finite impulse response estimate of the BOLD response locked to the onset of the cataplectic attacks as a function of peristimulus time (time bins of $2 \mathrm{~s}$, peristimulus timescale of $32 \mathrm{~s}$ ). To derive a grand average PSTH over NT1 patients, we first computed PSTHs within each subject and for each voxel of interest within each run, then averaged over sessions, and finally computed a grand average by computing over patients. Amy; amygdala; FG, fusiform gyrus; $L C$, locus ceruleus.

regions encompassing the bilateral (>right) opercular-insular cortex (global maxima), right amygdala, bilateral ventral striatum, and right nucleus accumbens (Fig. 5, Table 3). No higher BOLD signal increases were detected in the contrast laughter > cataplexy.

\section{Correlation between BOLD changes and clinical}

behavioral variables

We did not disclose any significant linear relationship between cataplexy-related BOLD changes and clinical polygraphic variables. Similarly, we did not find any correlation between laughter-induced
BOLD changes and clinical polygraphic variables. Moreover, no significant linear correlations were observed between the BOLD signal changes relative to the contrasts of interest and the number of smiles/ laughter events during scanning, as well as the postscanning ratings of the videos.

\section{Discussion}

In patients with NT1, cataplexy is most often triggered by positive emotions such as those associated with laughter, joking, or delight (Overeem et al., 1999; Dauvilliers et al., 2014). For more than 130 years this striking and odd connection to positive emo- 
Table 3. Regional brain responses to conditions of interest

\begin{tabular}{|c|c|c|c|c|c|c|}
\hline \multirow[b]{2}{*}{ Regions } & \multirow[b]{2}{*}{$L / R$} & \multicolumn{3}{|c|}{ MNI coordinates } & \multirow[b]{2}{*}{$B A$} & \multirow[b]{2}{*}{ Zscore } \\
\hline & & $x$ & $y$ & $z$ & & \\
\hline \multicolumn{7}{|l|}{ Cataplexy } \\
\hline AIC & $\mathrm{R}$ & 42 & 12 & 3 & 13 & 4.64 \\
\hline Precentral gyrus & L & -42 & -18 & 42 & 4 & 4.15 \\
\hline Amygdala & $\mathrm{R}$ & 24 & 6 & -16 & 34 & 4.12 \\
\hline Precentral gyrus & $\mathrm{R}$ & 44 & -20 & 36 & 4 & 4.11 \\
\hline Anterior cingulate gyrus & L & -4 & -22 & 40 & 24 & 3.88 \\
\hline Anterior cingulate gyrus & $\mathrm{R}$ & 2 & 0 & 42 & 24 & 3.86 \\
\hline Parahippocampal gyrus & L & -32 & 0 & -24 & 34 & 3.82 \\
\hline Nucleus accumbens & L & -4 & 12 & -12 & - & 3.70 \\
\hline Anterior cerebellum lobe & $\mathrm{R}$ & 38 & -56 & -26 & - & 3.62 \\
\hline Parahippocampal gyrus & $\mathrm{R}$ & 20 & -22 & -18 & 34 & 3.57 \\
\hline Thalamus & $\mathrm{R}$ & 8 & -16 & 0 & - & 3.55 \\
\hline Superior temporal gyrus & $\mathrm{R}$ & 66 & -34 & 18 & 42 & 3.42 \\
\hline Middle temporal gyrus & $\mathrm{R}$ & 52 & 2 & -26 & 21 & 3.42 \\
\hline Locus ceruleus & L & -10 & -28 & -12 & - & 3.42 \\
\hline Locus ceruleus & $\mathrm{R}$ & 10 & -28 & -12 & - & 3.37 \\
\hline Supplementary motor area & $\mathrm{R}$ & 8 & -16 & 64 & 6 & 3.37 \\
\hline Fusiform gyrus & $\mathrm{R}$ & 20 & 56 & -14 & 20 & 3.37 \\
\hline Thalamus & L & -10 & -10 & 18 & - & 3.33 \\
\hline VMPFC & $\mathrm{R}$ & 2 & 48 & -6 & 10 & 3.22 \\
\hline \multicolumn{7}{|l|}{ Laughter } \\
\hline Precentral gyrus & $\mathrm{R}$ & 52 & -14 & 34 & 4 & 3.93 \\
\hline Precentral gyrus & L & -48 & -14 & 32 & 4 & 3.73 \\
\hline Middle cingulate gyrus & L & 0 & 10 & 40 & 24 & 3.64 \\
\hline Middle cingulate gyrus & $\mathrm{R}$ & 4 & 2 & 40 & 24 & 3.34 \\
\hline \multicolumn{7}{|l|}{ Cataplexy > laughter } \\
\hline Anterior Insular Cortex & $\mathrm{R}$ & 42 & 12 & 4 & 13 & 4.33 \\
\hline Inferior frontal gyrus & $\mathrm{R}$ & 24 & 10 & -20 & 47 & 3.93 \\
\hline Nucleus accumbens & $\mathrm{R}$ & 6 & 14 & -10 & - & 3.60 \\
\hline Caudate head & $\mathrm{R}$ & 14 & 16 & -2 & - & 3.57 \\
\hline Amygdala & $\mathrm{R}$ & 24 & -2 & -22 & 34 & 3.50 \\
\hline Putamen & L & -28 & -10 & -8 & - & 3.44 \\
\hline AIC & L & -40 & 0 & 4 & 13 & 3.35 \\
\hline
\end{tabular}

Reported regions survived at a threshold level of $p<0.05$ corrected for FDR. L, left; $R$, right.

Table 4. First-level analysis results of BOLD changes related to cataplexy

\begin{tabular}{|c|c|c|c|c|c|c|c|c|}
\hline \multirow[b]{2}{*}{ Patient number } & \multirow[b]{2}{*}{ Side } & \multicolumn{7}{|c|}{ Regions of BOLD signal increase MNI coordinates $(x y z)$} \\
\hline & & Amy & VMPFC & $A C C$ & $\mathrm{AlC}$ & LC & Ant Pons & PAG \\
\hline \multirow[t]{2}{*}{2} & $\mathrm{~L}$ & $-262-12$ & $-848-4$ & -64614 & $-4020-14$ & - & - & - \\
\hline & $\mathrm{R}$ & $242-14$ & $1052-6$ & 12488 & 44280 & - & - & - \\
\hline \multirow[t]{2}{*}{4} & $\mathrm{~L}$ & - & - & - & - & - & - & - \\
\hline & $\mathrm{R}$ & $26-4-20$ & $1452-12$ & 20382 & $4424-14$ & - & - & - \\
\hline \multirow[t]{2}{*}{6} & $\mathrm{~L}$ & - & - & 一 & - & - & - & - \\
\hline & $\mathrm{R}$ & $202-22$ & 103612 & $6-1234$ & 42322 & $6-32-16$ & - & - \\
\hline \multirow[t]{2}{*}{9} & $L$ & - & $-462-4$ & 03224 & - & - & - & - \\
\hline & $\mathrm{R}$ & $280-22$ & $450-4$ & - & $36-4-12$ & - & - & - \\
\hline \multirow[t]{2}{*}{13} & $\mathrm{~L}$ & - & 一 & - & - & - & 一 & - \\
\hline & $\mathrm{R}$ & $224-16$ & $864-10$ & 43222 & $4410-8$ & - & $2-26-32$ & - \\
\hline \multirow[t]{2}{*}{15} & $\mathrm{~L}$ & $-22-2-20$ & - & 02028 & - & - & - & - \\
\hline & $\mathrm{R}$ & - & - & 42422 & 4282 & - & $2-22-30$ & - \\
\hline \multirow[t]{2}{*}{16} & L & - & $-1658-14$ & -2242 & - & $-2-34-30$ & - & - \\
\hline & $\mathrm{R}$ & $284-16$ & $1848-14$ & - & $406-8$ & - & - & - \\
\hline \multirow[t]{2}{*}{17} & $\mathrm{~L}$ & $-24-6-6$ & $-260-6$ & -603612 & $-38-1210$ & - & $-2-18-26$ & - \\
\hline & $\mathrm{R}$ & $22-4-6$ & - & - & $44-2-10$ & $4-36-16$ & $8-16-24$ & $2-30-6$ \\
\hline \multirow[t]{2}{*}{19} & L & - & $048-8$ & -23618 & - & - & - & - \\
\hline & $\mathrm{R}$ & - & - & - & - & - & - & $4-38-4$ \\
\hline \multirow[t]{2}{*}{21} & $L$ & - & - & - & - & - & - & - \\
\hline & $\mathrm{R}$ & - & - & - & - & - & - & - \\
\hline
\end{tabular}

Reported regions survived at a threshold level of $p<0.05$ corrected for FDR. L, left; R, right. Amy, amygdala; LC, locus ceruleus; PAG: periaqueductal gray.

tions has been recognized as a key aspect of cataplexy (Schenck et al., 2007), but only recently the neural mechanisms through which positive emotions trigger cataplexy have been partly clarified in animal models (Burgess et al., 2013; Oishi et al., 2013; Dauvilliers et al., 2014).
Our study shows, for the first time in humans, the brain structures whose neural activity is specifically associated with emotion-induced cataplexy. Importantly, drug-naive children and adolescents with recent onset NT1 help us to unravel the cerebral correlates of genuine cataplexy before the patients adopt 


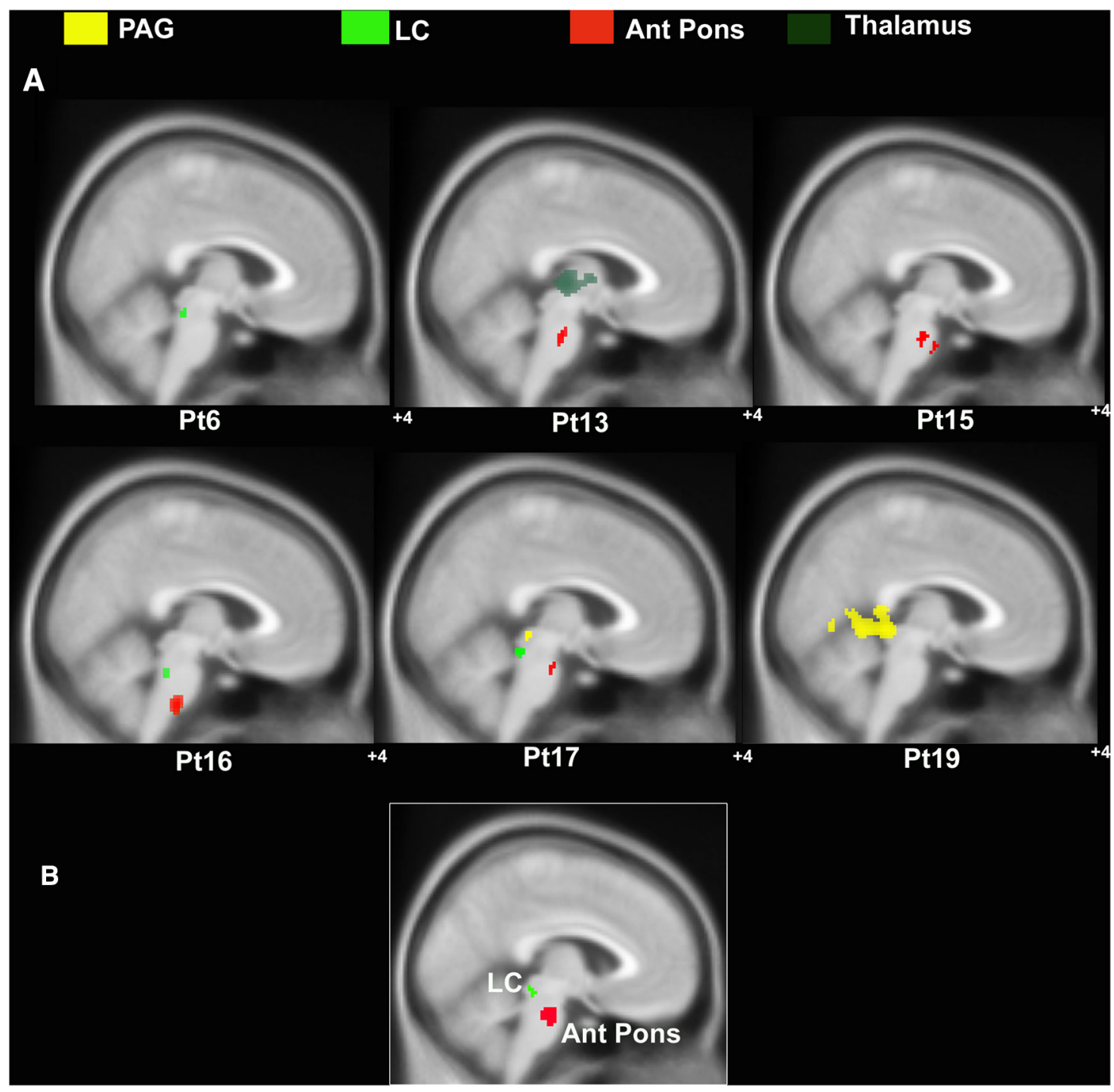

Figure 3. Brainstem-focused BOLD signal changes in NT1 patients at single-subject $(\boldsymbol{A})$ and group level ( $\boldsymbol{B} ; \boldsymbol{p}<0.05$ corrected for FDR). See main text and Table 4 for details. LC, locus ceruleus; Ant Pons: anteromedial pons.

the well known behavioral strategies ("tricks") to avoid cataplexy occurrence and before possible drug-induced effects (Overeem et al., 2011). Recent observations uncovered a discrete cataplexy phenotype in children close to disease onset. Children suffering from NT1, indeed, can present with frequent episodes of facial weakness (cataplectic facies) characterized by eyelid and mouth opening superimposed with partial or global muscle atonia triggered by emotions (Serra et al., 2008; Plazzi et al., 2011). This phenotype is more evident in younger patients close to disease onset (Plazzi et al., 2011; Pizza et al., 2013, 2014; Plazzi and Pizza, 2013) and also was reliably observed during emotional stimulation in the present $\mathrm{AMRI}$ paradigm.

Here, we observed that when NT1 patients showed behavioral signs of fun (smiles/laugh) without video-polygraphic evidence of cataplexy, fMRI revealed the involvement of a bilateral cortical network including the motor system and the ACC. Notably, we did not observe the involvement of corticalsubcortical regions that has been consistently observed in fMRI studies investigating humor detection and appreciation in healthy subjects, namely the mesolimbic reward areas, the ventromedial prefrontal cortex, the temporo-occipital junc- tion, the amygdala, and the periaqueductal gray (PAG; Goel and Dolan, 2001; Moran et al., 2004; Bartolo et al., 2006; Watson et al., 2007; Szameitat et al., 2010; Wattendorf et al., 2013). In contrast, when cataplexy occurred neural activity increased in a bilateral network that included cortical and subcortical regions involved in processing saliency and emotions (Mobbs et al., 2003; Seeley et al., 2007; Craig, 2009). In particular, during cataplexy BOLD signal increases encompassed the anterior insular cortex, the amygdala, the VMPFC, and the ventral striatum. Notably, we demonstrated that the cataplexy-related corticolimbic network shows an increased neural activity only when the subjects experience a high level of enjoyment. Indeed, the observed behavioral results clearly show a significant difference in the humor appreciation scores in the fMRI runs with cataplexy (i.e., higher scores) compared with the ones without cataplexy (i.e., lower scores). This behavioral difference could also explain the absence of increased BOLD signal in amygdala, insular cortex, and VMPFC during episodes of laughter without cataplexy. We can therefore infer that in NT1 cataplexy is associated with a marked increase in neural activity in suprapontine centers that physiologically 

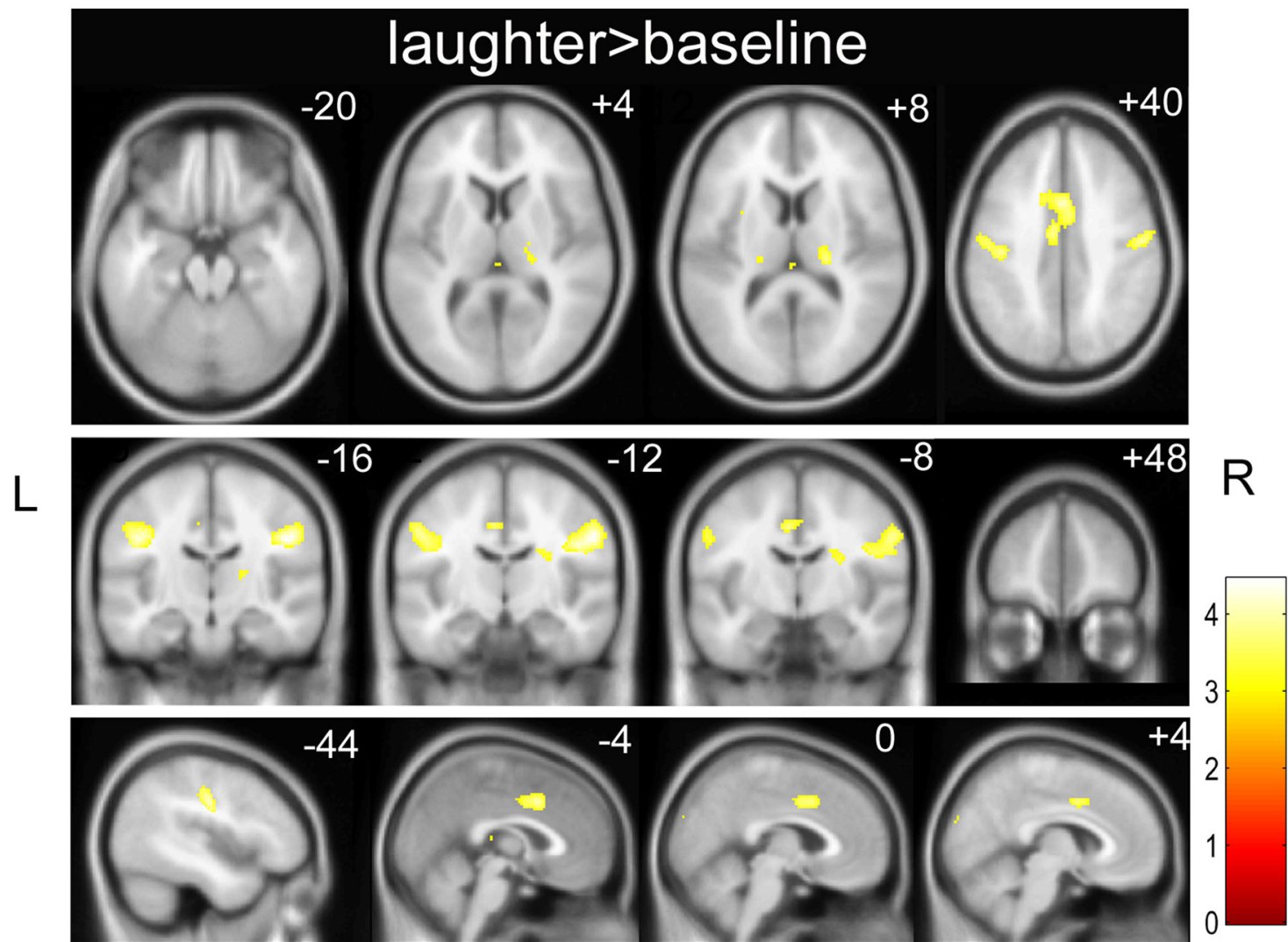

Figure 4. fMRI results related to laughter. Group-related (random-effect analysis) laughter-related BOLD findings. The BOLD changes ( $p<0.05$ corrected for FDR) are displayed on the axial, coronal, and sagittal T1-template image. See main text and Table 3 for details of activations. No decreases in BOLD signal were detected. L, left; $R$, right.

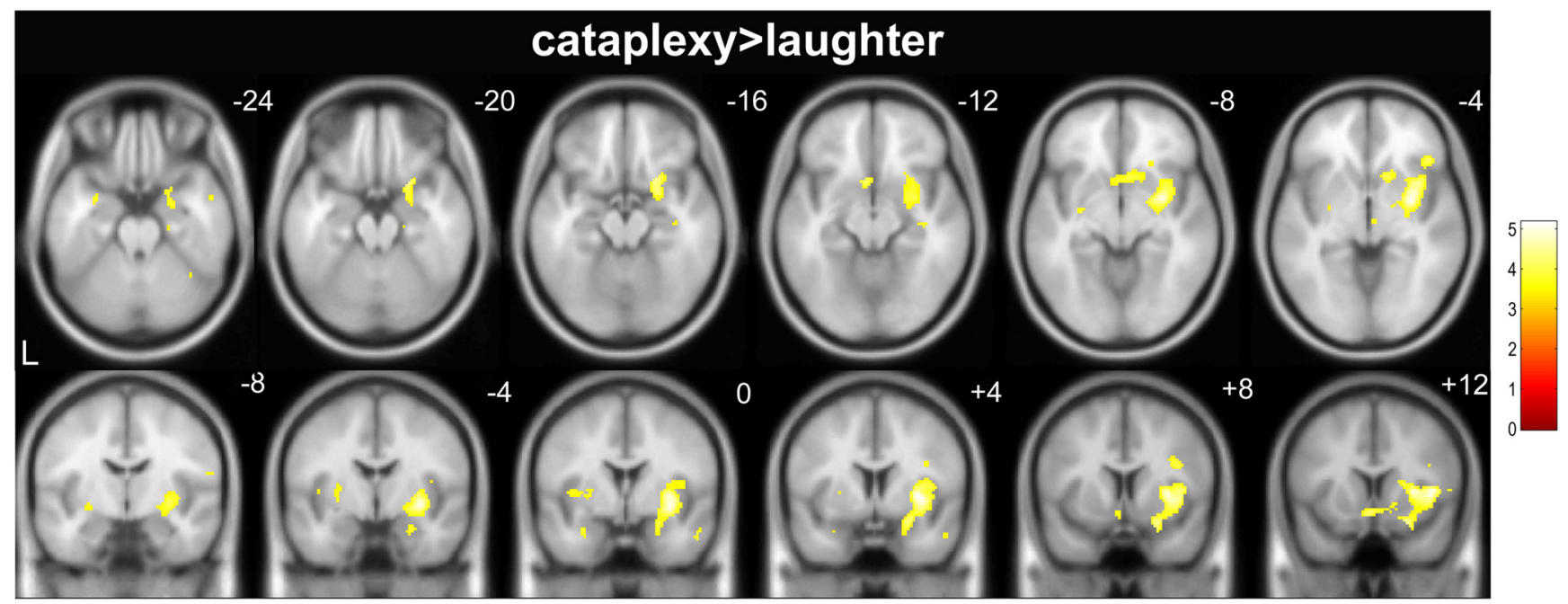

Figure 5. fMRI results related to the contrast cataplexy $>$ laughter. Group-level BOLD findings ( $p<0.05$ corrected for FDR) are displayed on the axial and coronal T1-template image. L, left. See main text and Table 3 for details of hemodynamic changes.

process emotions and rewards. It is probable that activity in these centers, and especially in the amygdala, can in turn lead to GABAergic inhibition of pontomedullary centers, which are known to mediate REM sleep muscle atonia (Hong et al., 2006; Dauvilliers et al., 2014). Interestingly, we also disclosed cataplexy-related increased activity in pontomesencephalic regions in the proximity of the locus ceruleus and midline pontine regions that could represent the final effectors of the brain mechanism that mediates cataplexy. Importantly, it must be underscored that our results do not support any direct role of the cortical (voluntary) motor system in the suprapontine mechanisms leading to atonia in cataplexy. Indeed, when comparing cataplexy versus laughter no cortical motor-premotor area was observed to be involved.

Overall, our results are convergent with several lines of evidence supporting the crucial importance of the amygdala in cataplexy. Previous event-related functional neuroimaging studies showed abnormal amygdala activity in adult NT1 pa- 
tients while seeing humorous photographic images and during aversive conditioning (Schwartz et al., 2008; Ponz et al., 2010a,b). All these studies, which investigated different aspects of emotion processing in NT1 patients, showed altered amygdala reactivity with respect to healthy volunteers. An altered response to emotional stimulation in NT1 is suggested also by neurophysiological studies disclosing a blunted autonomic, muscular cognitive response to unpleasant visual and acoustic stimuli (Tucci et al., 2003; Khatami et al., 2007). Importantly, animal models of narcolepsy strongly support an active role of amygdala neurons during cataplexy. Indeed, electrophysiological recordings from isolated cells in narcoleptic dogs demonstrate that increased activity of amygdala neurons is closely associated with cataplectic attacks (Gulyani et al., 2002), while bilateral lesions of the amygdala significantly reduce the frequency of cataplectic attacks in $\mathrm{Hcrt}^{-1-}$ mice (Burgess et al., 2013).

Concerning the role of the ACC/VMPFC, several experimental studies indicate that these regions may also play a critical role in cataplexy. Prior research suggests that these areas are activated in association with positive emotions and in the affective component of humor appreciation (Goel and Dolan, 2001; Craig, 2009). Activity in the ACC, as measured by PET, is correlated with subjective feelings of happiness, and fMRI studies show that the ACC is selectively activated by pleasurable visual stimuli and reward (Damasio et al., 2000; Knutson et al., 2003; Sabatinelli et al., 2007). Importantly, in reference to narcolepsy, the ACC/VMPFC also has an established role in triggering cataplexy in animal models. The ingestion of palatable foods (for example, chocolate), which trigger cataplexy in $\mathrm{Hcrt}^{-1-}$ mice, also activates neurons in the VMPFC, while inhibition of VMPFC neurons markedly reduces cataplectic attacks associated with positive emotional stimuli (Oishi et al., 2013). In addition, the ACC/VMPFC directly innervates the amygdala, which contains neurons that are active during cataplexy and innervate downstream brainstem regions involved in the regulation of muscle tone (Oishi et al., 2013). Accordingly, it has been recently reported that during cataplexy in rodent models hypersynchronous paroxysmal EEG theta bursts occur in the medial prefrontal cortex, and similar scalp paroxysmal EEG activities may appear in NT1 children close to disease onset during cataplectic events (Vassalli et al., 2013).

In this study the anterior insular cortex-frontal operculum region was the brain region with the highest increase of BOLD signal in relation to cataplexy. It is plausible that the observed insular activity represents a consequence of the autonomic and bodily changes related to cataplexy or to the visceral responses related to the pleasurable rewarding experience that immediately precedes/induces cataplexy. In this view, the anterior insular activity during cataplexy may code for the interoceptive representation of the body during humor appreciation (Moran et al., 2004; Craig, 2009). We cannot exclude that the insular cortex can exert a direct causative effect on the mechanisms leading to loss of muscle tone; however, no animal data presently support this hypothesis.

Finally, we observed a relatively asymmetric BOLD response during cataplexy that involved mainly right hemisphere corticolimbic structures. We believe that this difference can be principally attributed to the type of material used to elicit laughs (sight gags) rather than to the neurobiology of NT1. Indeed, whereas studies evaluating humor detection using material for which humor comprehension depends on language understanding showed principally left hemisphere responses (Mobbs et al., 2003), studies that used visual stimuli/sight gags uncovered more bilaterally distributed networks, or right-side prevalent BOLD responses (Watson et al., 2007).

Our findings demonstrate that the suprapontine regions whose activity is associated with cataplexy are the ones that physiologically process positive emotion and amusement/reward. These findings are in line with the well known notion that a sense of momentary muscle weakness associated with laughter can occur even in healthy individuals (Overeem et al., 1999), possibly mediated by the same neural pathway that we observed in NT1. In healthy humans, however, orexin neurons are active under conditions of high arousal and positive emotions (Mileykovskiy et al., 2005; Blouin et al., 2013), and directly innervate the ventrolateral PAG/lateral pontine tegmentum (Kaur et al., 2009; Dauvilliers et al., 2014). Therefore, in normal subjects any inhibition of these brainstem regions by the amygdala (or other suprapontine regions) would be counterbalanced by the orexin neurons and the subsequent monoamine activation, thus maintaining muscle tone (Burgess and Scammell, 2012; Clément et al., 2012). With the loss of orexin signaling in NT1 the inhibitory projections from the amygdala would go unopposed, resulting in cataplexy. Notably, we did not observe any BOLD signal changes in activity of the hypothalamic region during emotion stimulation (both during the laugh and during cataplexy) that could be the result of NT1 pathology.

Our study has limitations. First, to maximize the possibility of recording cataplexy during an fMRI session we developed a within-subject paradigm precisely tailored to the type of humor appreciated by each subject. Future studies should address whether differences are present during laughter in NT1 patients versus healthy controls beyond the occurrence of cataplexy. Indeed, our findings showed that during the laugh, in absence of cataplexy, only the voluntary motor networks for expressive laugh are present in NT1. The design of our experiment does not evaluate if the absence of "limbic" structures merely reflects the BOLD counterpart of a low level of humor detection/appreciation during the majority of laugh events or if it is related to the neurobiology of the disease. Second, BOLD imaging tells us limited information about the causal role of the different structures that were involved during cataplexy. Nevertheless, we provided for the first time a framework for the cortical and subcortical mechanisms involved in the downstream (brainstem-mediated) occurrence of cataplexy by positive emotions in humans.

\section{References}

American Academy of Sleep Medicine (2014) International classification of sleep disorders, ed 3. Darien, IL: American Academy of Sleep Medicine.

Avanzini P, Vaudano AE, Vignoli A, Ruggieri A, Benuzzi F, Darra F, Mastrangelo M, Dalla Bernardina B, Nichelli PF, Canevini MP, Meletti S (2014) Low frequency mu-like activity characterizes cortical rhythms in epilepsy due to ring chromosome 20. Clin Neurophysiol 125:239-249. CrossRef Medline

Bartolo A, Benuzzi F, Nocetti L, Baraldi P, Nichelli P (2006) Humor comprehension and appreciation: an FMRI study. J Cogn Neurosci 18:1789_ 1798. CrossRef Medline

Blouin AM, Fried I, Wilson CL, Staba RJ, Behnke EJ, Lam HA, Maidment NT, Karlsson KÆ, Lapierre JL, Siegel JM (2013) Human hypocretin and melanin-concentrating hormone levels are linked to emotion and social interaction. Nat Commun 4:1547. CrossRef Medline

Burgess CR, Scammell TE (2012) Narcolepsy: neural mechanisms of sleepiness and cataplexy. J Neurosci 32:12305-12311. CrossRef Medline

Burgess CR, Oishi Y, Mochizuki T, Peever JH, Scammell TE (2013) 
Amygdala lesions reduce cataplexy in orexin knock-out mice. J Neurosci 33:9734-9742. CrossRef Medline

Chabas D, Habert MO, Maksud P, Tourbah A, Minz M, Willer JC, Arnulf, I (2007) Functional imaging of cataplexy during status cataplecticus. Sleep 30:153-156. Medline

Chaudhary UJ, Rodionov R, Carmichael DW, Thornton RC, Duncan JS, Lemieux L (2012) Improving the sensitivity of EEG-fMRI studies of epileptic activity by modelling eye blinks, swallowing and other video-EEG detected physiological confounds. Neuroimage 61:1383-1393. CrossRef Medline

Clément O, Sapin E, Libourel PA, Arthaud S, Brischoux F, Fort P, Luppi PH (2012) The lateral hypothalamic area controls paradoxical (REM) sleep by means of descending projections to brainstem GABAergic neurons. J Neurosci 32:16763-16774. CrossRef Medline

Craig AD (2009) How do you feel—now? The anterior insula and human awareness. Nat Rev Neurosci 10:59-70. CrossRef Medline

Damasio AR, Grabowski TJ, Bechara A, Damasio H, Ponto LL, Parvizi J, Hichwa RD (2000) Subcortical and cortical brain activity during the feeling of self-generated emotions. Nat Neurosci 3:1049-1056. CrossRef Medline

Dauvilliers Y, Arnulf I, Mignot E (2007) Narcolepsy with cataplexy. Lancet 369:499-511. CrossRef Medline

Dauvilliers Y, Comte F, Bayard S, Carlander B, Zanca M, Touchon J (2010) A brain PET study in patients with narcolepsy-cataplexy. J Neurol Neurosurg Psychiatry 81:344-348. CrossRef Medline

Dauvilliers Y, Siegel JM, Lopez R, Torontali ZA, Peever JH (2014) Cataplexy-clinical aspects, pathophysiology and management strategy. Nat Rev Neurol 10:386-395. CrossRef Medline

Friston KJ, Williams S, Howard R, Frackowiak RS, Turner R (1996) Movement-related effects in fMRI time-series. Magn Reson Med 35:346355. CrossRef Medline

Friston KJ, Holmes AP, Price CJ, Büchel C, Worsley KJ (1999) Multisubject fMRI studies and conjunction analyses. Neuroimage 10:385-396. CrossRef Medline

Goel V, Dolan RJ (2001) The functional anatomy of humor: segregating cognitive and affective components. Nat Neurosci 4:237-238. CrossRef Medline

Gulyani S, Wu MF, Nienhuis R, John J, Siegel JM (2002) Cataplexy-related neurons in the amygdala of the narcoleptic dog. Neuroscience 112:355365. CrossRef Medline

Hong SB, Tae WS, Joo EY (2006) Cerebral perfusion changes during cataplexy in narcolepsy patients. Neurology 66:1747-1749. CrossRef Medline

Kaur S, Thankachan S, Begum S, Liu M, Blanco-Centurion C, Shiromani PJ (2009) Hypocretin-2 saporin lesions of the ventrolateral periaqueductal gray (vlPAG) increase REM sleep in hypocretin knock-out mice. PLoS One 4:e6346. CrossRef Medline

Khatami R, Birkmann S, Bassetti CL (2007) Amygdala dysfunction in narcolepsy-cataplexy. J Sleep Res 16:226-229. CrossRef Medline

Knutson B, Fong GW, Bennett SM, Adams CM, Hommer D (2003) A region of medial prefrontal cortex tracks monetarily rewarding outcomes: characterization with rapid event-related fMRI. Neuroimage 18:263-272. CrossRef Medline

Littner MR, Kushida C, Wise M, Davila DG, Morgenthaler T, Lee-Chiong T, Hirshkowitz M, Daniel LL, Bailey D, Berry RB, Kapen S, Kramer M, Kramer M (2005) Standards of Practice Committee of the American Academy of Sleep Medicine. Practice parameters for clinical use of the multiple sleep latency test and the maintenance of wakefulness test. Sleep 28:113-121. Medline

Longstreth WT Jr, Koepsell TD, Ton TG, Hendrickson AF, van Belle G (2007) The epidemiology of narcolepsy. Sleep 30:13-26. Medline

Melendres MC, Lutz JM, Rubin ED, Marcus CL (2004) Daytime sleepiness and hyperactivity in children with suspected sleep-disordered breathing. Pediatrics 114:768-775. CrossRef Medline

Mileykovskiy BY, Kiyashchenko LI, Siegel JM (2005) Behavioral correlates of activity in identified hypocretin/orexin neurons. Neuron 46:787-798. CrossRef Medline

Mobbs D, Greicius MD, Abdel-Azim E, Menon V, Reiss AL (2003) Humor modulates the mesolimbic reward centers. Neuron 40:1041-1048. CrossRef Medline

Moran JM, Wig GS, Adams RB Jr, Janata P, Kelley WM (2004) Neural correlates of humor detection and appreciation. Neuroimage 21:1055-1060. CrossRef Medline
Oishi Y, Williams RH, Agostinelli L, Arrigoni E, Fuller PM, Mochizuki T, Saper CB, Scammell TE (2013) Role of the medial prefrontal cortex in cataplexy. J Neurosci 33:9743-9751. CrossRef Medline

Oldfield RC (1971) The Assessment and analysis of handedness: the Edinburgh Inventory. Neuropsychologia 9:97-113. CrossRef Medline

Overeem S, Lammers GJ, van Dijk JG (1999) Weak with laughter. Lancet 354:838. CrossRef Medline

Overeem S, van Nues SJ, van der Zande WL, Donjacour CE, van Mierlo P, Lammers GJ (2011) The clinical features of cataplexy: a questionnaire study in narcolepsy patients with and without hypocretin-1 deficiency. Sleep Med 12:12-18. CrossRef Medline

Partinen M, Kornum BR, Plazzi G, Jennum P, Julkunen I, Vaarala O (2014) Narcolepsy as an autoimmune disease: the role of H1N1 infection and vaccination. Lancet Neurol 13:600-613. CrossRef Medline

Peyron C, Faraco J, Rogers W, Ripley B, Overeem S, Charnay Y,Nevsimalova S, Aldrich M, Reynolds D, Albin R, Li R, Hungs M, Pedrazzoli M, Padigaru M, Kucherlapati M, Fan J, Maki R, Lammers GJ, Bouras C, Kucherlapati R, et al. (2000) A mutation in case of early onset narcolepsy and a generalized absence of hypocretin peptides in human narcoleptic brains. Nat Med 6:991-997. CrossRef Medline

Pizza F, Franceschini C, Peltola H, Vandi S, Finotti E, Ingravallo F, Nobili L, Bruni O, Lin L, Edwards MJ, Partinen M, Dauvilliers Y, Mignot E, Bhatia KP, Plazzi G (2013) Clinical and polysomnographic course of childhood narcolepsy with cataplexy. Brain 136:3787-3795. CrossRef Medline

Pizza F, Peltola H, Sarkanen T, Moghadam KK, Plazzi G, Partinen M (2014) Childhood narcolepsy with cataplexy: comparison between post-H1N1 vaccination and sporadic cases. Sleep Med 15:262-265. CrossRef Medline

Plazzi G, Pizza F (2013) Childhood narcolepsy with cataplexy: a newly reported phenotype of an old disease? Sleep Med 14:810-811. CrossRef Medline

Plazzi G, Pizza F, Palaia V, Franceschini C, Poli F, Moghadam KK, Cortelli P, Nobili L, Bruni O, Dauvilliers Y, Lin L, Edwards MJ, Mignot E, Bhatia KP (2011) Complex movement disorders at disease onset in childhood narcolepsy with cataplexy. Brain 134:3477-3489. CrossRef Medline

Ponz A, Khatami R, Poryazova R, Werth E, Boesiger P, Bassetti CL, Schwartz S (2010a) Abnormal activity in reward brain circuits in human narcolepsy with cataplexy. Ann Neurol 67:190-200. CrossRef Medline

Ponz A, Khatami R, Poryazova R, Werth E, Boesiger P, Schwartz S, Bassetti CL (2010b) Reduced amygdala activity during aversive conditioning in human narcolepsy. Ann Neurol 67:394-398. CrossRef Medline

Reiss AL, Hoeft F, Tenforde AS, Chen W, Mobbs D, Mignot EJ (2008) Anomalous hypothalamic responses to humor in cataplexy. PLoS One 3:e2225. CrossRef Medline

Rubboli G, d'Orsi G, Zaniboni A, Gardella E, Zamagni M, Rizzi R, Meletti S, Valzania F, Tropeani A, Tassinari CA (2000) A video-polygraphic analysis of the cataplectic attack. Clin Neurophysiol 111 [Suppl 2]:S120-S128. CrossRef Medline

Ruggieri A, Vaudano AE, Benuzzi F, Serafini M, Gessaroli G, Farinelli V, Nichelli PF, Meletti S (2015) Mapping (and modeling) physiological movements during EEG-fMRI recordings: the added value of the VIDEO acquired simultaneously. J Neurosci Methods 239:223-237. CrossRef Medline

Sabatinelli D, Bradley MM, Lang PJ, Costa VD, Versace F (2007) Pleasure rather than salience activates human nucleus accumbens and medial prefrontal cortex. J Neurophysiol 98:1374-1379. CrossRef Medline

Schenck CH, Bassetti CL, Arnulf I, Mignot E (2007) English translations of the first clinical reports on narcolepsy and cataplexy by Westphal and Gélineau in the late 19th century, with commentary. J Clin Sleep Med 3:301-311. Medline

Schwartz S, Ponz A, Poryazova R, Werth E, Boesiger P, Khatami R, Bassetti CL (2008) Abnormal activity in hypothalamus and amygdala during humour processing in human narcolepsy with cataplexy. Brain 131:514522. CrossRef Medline

Seeley WW, Menon V, Schatzberg AF, Keller J, Glover GH, Kenna H, Reiss AL, Greicius MD (2007) Dissociable intrinsic connectivity networks for salience processing and executive control. J Neurosci 27:2349-2356. CrossRef Medline

Serra L, Montagna P, Mignot E, Lugaresi E, Plazzi G (2008) Cataplexy features in childhood narcolepsy. Mov Disord 23:858-865. CrossRef Medline

Szameitat DP, Kreifelts B, Alter K, Szameitat AJ, Sterr A, Grodd W, Wildgruber D (2010) It is not always tickling: distinct cerebral responses during 
perception of different laughter types. Neuroimage 53:1264-1271. CrossRef Medline

Thannickal TC, Moore RY, Nienhuis R, Ramanathan L, Gulyani S, Aldrich M, Cornford M, Siegel JM (2000) Reduced number of hypocretin neurons in human narcolepsy. Neuron 27:469-474. CrossRef Medline

Tucci V, Stegagno L, Vandi S, Ferrillo F, Palomba D, Vignatelli L, FeriniStrambi L, Montagna P, Plazzi G (2003) Emotional information processing in patients with narcolepsy: a psychophysiologic investigation. Sleep 26:558-564. Medline

Vassalli A, Dellepiane JM, Emmenegger Y, Jimenez S, Vandi S, Plazzi G, Franken P, Tafti M (2012) Electroencephalogram paroxysmal $\theta$ characterizes cataplexy in mice and children. Brain 136:1592-1608. CrossRef Medline

Vaudano AE, Ruggieri A, Tondelli M, Avanzini P, Benuzzi F, Gessaroli G,Cantalupo G, Mastrangelo M, Vignoli A, Bonaventura CD, Canevini
MP, Bernardina BD, Nichelli PF, Meletti S (2014) The visual system in eyelid myoclonia with absences. Ann Neurol 76:412-427. CrossRef Medline

Vetrugno R, D’Angelo R, Moghadam KK, Vandi S, Franceschini C, Mignot E, Montagna P, Plazzi G (2010) Behavioural and neurophysiological correlates of human cataplexy: a video-polygraphic study. Clin Neurophysiol 121:153-162. CrossRef Medline

Watson KK, Matthews BJ, Allman JM (2007) Brain activation during sight gags and language-dependent humor. Cereb Cortex 17:314-324. CrossRef Medline

Wattendorf E, Westermann B, Fiedler K, Kaza E, Lotze M, Celio MR (2013) Exploration of the neural correlates of ticklish laughter by functional magnetic resonance imaging. Cereb Cortex 23:1280-1289. CrossRef Medline 